\title{
Educação superior e desenvolvimento regional: o caso da UNOESC-SMO
}

Fábio Zambiasi

Elis Regina Mulinari Zanin

\begin{abstract}
Resumo
Este artigo tem por objetivo analisar a relação existente entre a Instituição de Ensino Superior UNOESC São Miguel do Oeste e o desenvolvimento da região em que ela atua a partir da percepção dos coordenadores de curso. Para a realização do estudo adotou-se uma abordagem qualitativa; quanto ao enfoque, exploratório; e quanto aos procedimentos, um estudo de caso; foram entrevistados os coordenadores dos 14 cursos ofertados no ano de 2019 na UNOESC São Miguel do Oeste. O estudo demonstrou que, para os coordenadores de curso, o desenvolvimento de uma região é consequência de seu crescimento econômico e social. Também se constataram interações entre as atividades dos cursos ofertados e a comunidade regional. Além disso, observou-se o compromisso da UNOESC São Miguel do Oeste em formar alunos com habilidades e competências para contribuírem para o desenvolvimento de sua região de atuação. A conclusão do estudo é de que a UNOESC São Miguel do Oeste, a partir de suas ações e atividades e da formação proporcionada aos seus egressos, pode ser reconhecida como uma Instituição de Ensino Superior promotora do desenvolvimento regional.
\end{abstract}

Palavras-chave | Desenvolvimento regional; Instituições de Ensino Superior; São Miguel do Oeste; UNOESC.

Classificação JEL | I23 O15 R11

\section{Higher Education and regional development: the case of UNOESC-SMO}

\begin{abstract}
This article aims to analyze the relation between the Higher Education Institution Unoesc São Miguel do Oeste and the development of the region in which it operates, based on the perception of the course coordinators.. For the development of the study, a qualitative approach was adopted, with an exploratory focus, and as for the procedures, a case study, being interviewed the coordinators of the fourteen courses offered in 2019 at Unoesc São Miguel do Oeste. The study showed that, for course coordinators, the development of a region is a consequence of its economic and social growth. Likewise, interactions between the activities of
\end{abstract}


Unoesc São Miguel do Oeste courses and the regional community were observed. In addition, Unoesc São Miguel do Oeste's commitment to training students with skills and competencies to contribute, mainly, to the development of their region of activity, was observed. With the conclusion of the study, it became evident that Unoesc São Miguel do Oeste, through its actions and activities and the training provided to graduates, can be recognized as a Higher Education Institution promoting regional development.

Keywords | Higher Education Institutions; regional development; São Miguel do Oeste; UNOESC.

\title{
JEL Classification | I23 O15 R11
}

\section{Educación Superior y desarrollo regional: el caso de la UNOESC-SMO}

\begin{abstract}
Resumen
Este artículo tiene como objetivo analizar la relación entre la Institución de Educación Superior UNOESC São Miguel do Oeste y el desarrollo de la región de operación desde la perspectiva de los coordinadores del curso. Para la realización del estudio se adoptó un enfoque cualitativo, en cuanto al abordaje, exploratorio, y al respecto de los procedimientos, un estudio de caso, siendo entrevistados los coordinadores de los 14 cursos ofrecidos en 2019 en UNOESC São Miguel do Oeste. El estudio mostró que, para los coordinadores de cursos, el desarrollo de una región es consecuencia de su crecimiento económico y social. Asimismo, se constataron interacciones entre las actividades de los cursos ofrecidos y la comunidad regional. Además, se observó el compromiso de la UNOESC São Miguel do Oeste de formar estudiantes con habilidades y competencias para contribuir al desarrollo de su región de actuación. Con la conclusión del estudio se hizo evidente que UNOESC São Miguel do Oeste, a partir de sus acciones y actividades y de la capacitación brindada a los egresados, puede ser reconocida como una Institución de Educación Superior promotora del desarrollo regional.
\end{abstract}

Palabras clave | Desarrollo regional; Instituciones de Educación Superior; São Miguel do Oeste; UNOESC.

Clasificación JEL | I23 O15 R11

\section{Introdução}

Assumindo o papel de promotoras do desenvolvimento regional, as Instituições de Ensino Superior (IES) são conhecidas como agentes importantes para a criação e disseminação de conhecimentos. Por meio do desenvolvimento de suas atividades, as IES conseguem criar inovações e produzir conhecimento científico (CHIARINI; VIEIRA; ZORZIN, 2012). Dentro do contexto das IES, as universidades, em específico, constituem-se com base na indissociabilidade entre suas atividades de 
ensino, pesquisa e extensão, e são responsáveis pela multiplicação de diversos efeitos em suas regiões de atuação (REGO; CALEIRO, 2012).

Do mesmo modo, o Desenvolvimento Regional pode ser compreendido como um processo influenciado pela interação entre as IES, as empresas e a sociedade civil. Diante disso, os processos de desenvolvimento de uma região estão atrelados a transformações econômicas, políticas, culturais e sociais que ocorrem na sociedade e que resultam em novas possibilidades de crescimento (OLIVEIRA, 2002). Sendo assim, a atuação das IES pode apresentar contribuições nos processos de Desenvolvimento Regional. Além disso, as contribuições geradas em cada região são diferentes por conta das características e dinâmicas regionais, cabendo assim, a necessidade de avaliar separadamente cada região para melhor compreender contribuições e relações entre as IES e o Desenvolvimento Regional.

Dentro deste contexto, o presente estudo busca encontrar resposta para a seguinte problemática: qual é a relação entre a Universidade do Oeste de Santa Catarina (Unoesc) São Miguel do Oeste (SMO) e o desenvolvimento da região de atuação? A relevância da presente pesquisa, no que tange a IES estudada, está no mapeamento e mensuração dos benefícios gerados no desenvolvimento regional. No tocante à sociedade, sua importância está na identificação e análise das principais ações e atividades desenvolvidas pela IES. Do mesmo modo, o meio teóricocientífico é favorecido com a apresentação e publicação de uma nova e importante pesquisa, a qual possibilita aos estudiosos envolvidos um entendimento amplo sobre o tema estudado, além de influenciar o surgimento de novas investigações que aprofundem a questão.

Nesta perspectiva, o presente estudo tem por objetivo geral analisar a relação existente entre a UNOESC-SMO e o desenvolvimento da região de atuação a partir da percepção dos coordenadores de curso. Para tanto, estabeleceu-se como objetivos específicos: a) Caracterizar a IES analisada; b) Identificar a percepção dos coordenadores dos cursos da IES sobre o termo Desenvolvimento Regional; c) Descrever as ações e atividades realizadas pelos cursos da IES que contribuem para o desenvolvimento socioeconômico regional; e d) Identificar as contribuições geradas pelos egressos na comunidade regional em decorrência da formação nos cursos da IES.

Sendo assim, este artigo se organiza em cinco seções principais. A primeira aborda o ensino superior e as Instituições de Ensino Superior. A segunda, trata sobre o Desenvolvimento Regional e o papel das Instituições de Ensino Superior. A terceira seção apresenta os aspectos metodológicos do estudo. A quarta apresenta a análise e as discussões dos resultados. E, por fim, são apresentadas as considerações finais do estudo. 


\section{O ensino superior e as Instituições de Ensino Superior}

Nos últimos anos foi observado um crescimento significativo no número de IES no Brasil. No ano 2000, havia um total de 1.180 IES no país, das quais 1.004 eram privadas, e 176 públicas (INEP, 2001). Em 2017, havia 2.448 IES, das quais 2.152 de ensino privado, e 296 de ensino público (INEP, 2017).

Nesta perspectiva, a expansão das IES no Brasil foi acompanhada pelo crescimento no número de matrículas nessa modalidade. No ano de 2000, havia 2.694.245 matrículas no ensino superior (INEP, 2001), e em 2017 havia 8.290.911 matrículas (INEP, 2017). Diante do exposto, é importante destacar que o aumento, tanto de IES, quanto de matrículas, foi desencadeado inicialmente pela maior demanda da população por qualificação, junto ao incremento de políticas de democratização e acesso a esse nível de ensino, além da crescente participação do setor privado no oferecimento de cursos de ensino superior (SALATA, 2018).

Historicamente, segundo Ramos, Turmena e Nascimento (2017), tem-se como características marcantes do ensino superior a dificuldade de acesso e permanência por grande parte da população. Diante disso, pode-se considerar que o crescimento e a democratização do acesso ao ensino superior foram influenciados pelos processos de produção capitalista que exigiam maiores níveis de qualificação dos profissionais. Desse modo, em muitos casos, o aumento no número de pessoas frequentando o ensino superior esteve atrelado às demandas de qualificação profissional para o exercício de atividades.

Do mesmo modo, com a conclusão do ensino médio, os alunos precisam construir seus projetos de futuro, e, para isso, necessitam decidir quais caminhos devem seguir para continuar adquirindo conhecimentos. Para Jordani et al. (2014), a vida acadêmica é um dos meios pelos quais os jovens se transformam, e o acesso aos estudos de ensino superior consiste em um dos principais requisitos para obter melhores recompensas pessoais e profissionais.

Ao mesmo tempo, as IES são compreendidas como agentes importantes para a criação e disseminação de conhecimentos tanto a nível regional quanto nacional e internacional. As IES, e mais especificamente as universidades, por meio do desenvolvimento de pesquisas básicas e aplicadas, do desenvolvimento humano e da engenharia, conseguem criar inovações e produzir conhecimento científico. Sendo assim, as IES podem servir como incubadoras de ideias e conhecimentos para que estes possam ser desenvolvidos, transferidos e aplicados de forma benéfica na sociedade (CHIARINI; VIEIRA; ZORZIN, 2012).

Cabe destacar que as IES são regidas pela Constituição Federal de 1988, sendo classificadas em instituições públicas e privadas. As IES públicas são criadas ou incorporadas, mantidas e administradas pelo poder público. As privadas são mantidas e administradas por pessoas físicas ou jurídicas, dividindo-se em 
instituições com fins lucrativos e sem fins lucrativos (MONDINI; RODRIGUES, 2005).

As instituições com fins lucrativos são instituídas por pessoas físicas ou jurídicas de direito privado. Do mesmo modo, as sem fins lucrativos são instituídas de acordo com sua vocação social, podendo ser instituição comunitária (tem em sua entidade mantenedora representantes da sociedade), confessional (originada por motivação confessional ou ideológica) e filantrópica (presta educação e assistência social para a população sem cobrar retornos financeiros) (MONDINI; RODRIGUES, 2005).

Além disso, segundo o Decreto $\mathrm{n}^{\circ}$ 9.235/17, as IES se dividem em faculdades, centros universitários e universidades. Neste sentido, as instituições são credenciadas inicialmente como faculdades, e posteriormente, com o seu padrão de qualidade satisfatório, conseguem ser credenciadas como universidades ou centros universitários. Assim, enquanto os centros universitários oferecem cursos e programas de educação superior baseados prioritariamente no ensino, as universidades ofertam cursos e programas de educação superior baseados na indissociabilidade entre as atividades de ensino, pesquisa e extensão (BRASIL, 2017).

\section{Desenvolvimento Regional e o papel das Instituições de Ensino Superior}

Historicamente, compreende-se que a articulação e a interação existente entre as economias regionais e nacionais é um ponto considerável quando o assunto é desenvolvimento regional. Segundo Monteiro Neto, Brandão e Castro (2017), é necessário que haja uma interligação entre os diversos setores da economia, onde a presença de desconexões entre os elos existentes provoca a criação de ilhas isoladas de crescimento, sem o apoio dinâmico de outros setores que poderiam contribuir nos processos de crescimento e desenvolvimento. Além disso, os autores enfatizam que as regiões com maior diversidade e dinâmicas regionais tendem a influenciar o crescimento de regiões menos desenvolvidas.

Dentro desse contexto, ao falar de crescimento econômico e desenvolvimento é importante destacar as diferenças entre ambos. Segundo Vasconcellos e Garcia (2014, p. 242), o crescimento é compreendido como "o crescimento contínuo da renda per capita ao longo do tempo". Quanto ao desenvolvimento, os autores explicam que este envolve a inclusão de "alterações da composição do produto e a alocação dos recursos pelos diferentes setores da economia, de forma a melhorar os indicadores de bem-estar econômico e social (pobreza, desemprego, desigualdade, condições de saúde, alimentação, educação e moradia".

Desse modo, pode-se compreender a existência de uma relação entre o crescimento econômico, envolvendo aspectos quantitativos, e o desenvolvimento, relacionado a aspectos qualitativos. Segundo Oliveira (2002, p. 40), o "desenvolvimento nada mais é que o crescimento - incrementos positivos no produto e na renda - 
transformado para satisfazer as mais diversificadas necessidades do ser humano, tais como: saúde, educação, habitação, transporte, alimentação, lazer, dentre outras". Sendo assim, o desenvolvimento está atrelado, em muitos casos, ao crescimento econômico, de modo que o aumento dos níveis quantitativos de uma região pode possibilitar o alcance do desenvolvimento regional.

Neste contexto, as IES, por meio do seu funcionamento e da realização das suas atividades, conseguem se tornar multiplicadoras de diversos efeitos e contribuições em suas regiões de atuação. Segundo Rego e Caleiro (2012), os efeitos e contribuições proporcionados pelas IES compreendem tanto a demanda por colaboradores, serviços e produtos, quanto a oferta de uma população com maior nível de conhecimento e qualificação. Por sua vez, Chiarello (2015, p. 245) coloca que "o papel da universidade é determinante no desenvolvimento regional na medida em que as relações estabelecidas entre os agentes - universidades, empresas, sociedade civil, promovem o desenvolvimento". Além disso, para haver um maior número de efeitos e contribuições na sociedade é necessário que os agentes presentes no território se aproximem e interajam com as IES.

Desse modo, é importante destacar que as contribuições proporcionadas pelas IES em suas regiões de atuação não dependem unicamente do desenvolvimento de suas ações e atividades, mas, sim, da interação estabelecida entre os agentes territoriais. Segundo Rego e Caleiro (2012, p. 03), "os efeitos das IES decorrentes do exercício das suas funções - ensino, investigação e extensão - são tanto mais significativos quanto mais o território se apropriar dos 'outputs' das IES". Sendo assim, é necessário haver um engajamento e um trabalho conjunto entre as atividades das IES e a comunidade regional, em que tanto esta quanto aquelas devem manter-se em interação para a obtenção de contribuições no desenvolvimento regional.

Além disso, Frantz (2002, p. 16) destaca que o desenvolvimento "é um processo que contém elementos culturais, políticos, econômicos e tecnológicos. O desenvolvimento regional, além disso, precisa ser um processo de agregação de poder e nesse sentido a universidade pode e deve contribuir". Dessa forma, é notório que as relações sociais existentes entre os agentes territoriais são a base para o desenvolvimento regional. A interação entre uma IES e a sua comunidade regional se torna o ponto fundamental desse processo, seja no oferecimento de pessoas com maior nível de conhecimento e qualificação, na realização de ações e atividades que visam melhorar a qualidade de vida, no aumento da eficiência das organizações por meio da interação entre IES e organizações, ou, ainda, na demanda por serviços e colaboradores presente na região.

No que se refere à demanda por serviços e colaboradores, Hoff, Martin e Sopeña (2011) destacam que uma universidade gera inúmeras modificações na infraestrutura local em virtude da demanda de diferentes serviços pelas pessoas ligadas direta ou indiretamente a ela. Por sua vez, Goebel e Miura (2004) colocam que os serviços decorrentes do meio universitário incluem restaurantes, bares, 
livrarias, atividades de lazer, infraestrutura de transportes e alojamentos, entre outros. Além disso, essas atividades locais são importantes, pois movimentam transações financeiras na economia regional.

Ao mesmo tempo, Hoff, Martin e Sopeña (2011) enfatizam que as universidades auxiliam nos processos de crescimento e desenvolvimento de suas regiões de atuação, seja pela movimentação financeira na economia regional, ou pela contribuição na formação de profissionais qualificados. Ou seja, as universidades contribuem com a demanda de pessoal e com a movimentação de recursos financeiros, como salários, investimentos em obras e equipamentos, além de despesas para custear alunos. Do mesmo modo, proporcionam um ambiente de inovação, gerando aumento de mão de obra especializada por meio do desenvolvimento intelectual das pessoas que com ela interagem (HOFF; MARTIN; SOPEÑA, 2011).

Rolim e Serra (2009) destacam que as IES são muito importantes para a qualificação da força de trabalho, para a solução de problemas locais, para aumento do nível de conhecimento da população, além de contribuírem para a inovação e, consequentemente, auxiliar na produtividade local por meio do desenvolvimento de suas atividades de pesquisa. Além disso, Casado, Siluk e Zampiere (2012) enfatizam que as IES, por meio de suas ideias e ações, tornam-se os agentes de inovação e conhecimento mais indicados para a resolução de problemas comuns existentes na sociedade.

Por outro lado, em uma análise mais específica das atividades das IES, observa-se com base no artigo 207 da Constituição Federal de 1988, que a sua manutenção é baseada na indissociabilidade entre as atividades de ensino, pesquisa e extensão (BRASIL, 1988). Nessa perspectiva, Diehl e Terra (2017) destacam que é por meio dessa tríade que ocorre o relacionamento entre a academia e a comunidade regional, permitindo o pensar e a reflexão acerca da realidade social existente. Além disso, Diehl e Terra (2017) enfatizam que o desenvolvimento de pesquisas é um elemento central para avaliar e estudar contextos regionais e, consequentemente, produzir conhecimentos importantes para orientar as ações e as políticas voltadas para a melhoria dos contextos regionais.

Dentro desse contexto, torna-se importante especificar as atividades que compõem a tríade ensino, pesquisa e extensão. Segundo Sleutjes (1999), as atividades de ensino são responsáveis pela elevação da reflexão crítica, possibilitando entender as condições do contexto social, histórico e cultural onde os indivíduos se inserem. Por sua vez, as atividades de pesquisa têm seu foco voltado na expansão e no aprofundamento dos conhecimentos atuais, investigando a realidade, descobrindo novas possibilidades e soluções para problemas existentes. Quanto às atividades de extensão, o foco está na aplicação e na transferência dos conhecimentos para a sociedade, os quais podem ser gerados pelas próprias atividades de ensino e pesquisa desenvolvidas dentro das IES, permitindo, assim, contribuições significativas para 
a população envolvida nesse processo de transferência de conhecimentos (SLEUTJES, 1999).

Desse modo, pode-se compreender que as atividades das IES apresentam relações importantes com o Desenvolvimento Regional, dado que a maior parte das atividades procuram ampliar o nível de conhecimento da população, o qual, consequentemente, gera impactos e contribuições nos contextos regionais. Sendo assim, conforme apontado por Rego e Caleiro (2012), a atuação das IES se baseia no desenvolvimento de pessoas, de organizações, do mercado de trabalho, e da qualificação profissional. Seu funcionamento resulta em impactos, contribuições e mudanças que permitem auxiliar no alcance do desenvolvimento regional.

\section{Aspectos metodológicos}

O presente estudo foi realizado na UNOESC-SMO, contemplando todos os coordenadores dos 14 cursos, das seis áreas do conhecimento, ofertados no ano de 2019. Desse modo, foram entrevistados 12 coordenadores de curso, sendo que um deles atuava três cursos. Sendo assim, na área de Ciências Agrárias, entrevistou-se o coordenador do curso de Medicina Veterinária, na área de Ciências da Educação, entrevistou-se os coordenadores dos cursos de Pedagogia e Licenciatura em Educação Física, na área de Ciências da Vida e Saúde, entrevistou-se os coordenadores dos cursos de Bacharelado em Educação Física, Enfermagem, Farmácia, Fisioterapia e Psicologia, na área de Ciências Exatas e Tecnológicas, entrevistou-se os coordenadores dos cursos de Arquitetura e Urbanismo, Ciências da Computação e Engenharia Civil, na área de Ciência Jurídica, entrevistou-se o coordenador do curso de Direito, e na área de Ciências Sociais, entrevistou-se os coordenadores dos cursos de Administração e Ciências Contábeis.

Neste sentido, os coordenadores de curso foram selecionados a partir do método da população total. No tocante ao delineamento, a pesquisa apresentou uma abordagem qualitativa. O uso dessa abordagem, de acordo com Gil (2008), propicia o aprofundamento da investigação das questões relacionadas ao fenômeno em estudo e das suas relações. Quanto aos objetivos, classifica-se como exploratória, que, segundo Gil (2008, p. 27), "são desenvolvidas com o objetivo de proporcionar visão geral, de tipo aproximativo, acerca de determinado fato. Este tipo de pesquisa é realizado especialmente quando o tema escolhido é pouco explorado".

Quanto aos procedimentos, a pesquisa se classifica como um estudo de caso. Segundo Gil (2008, p. 57) "o estudo de caso é caracterizado pelo estudo profundo e exaustivo de um ou de poucos objetos, de maneira a permitir o seu conhecimento amplo e detalhado". Com o intuito de atender aos objetivos iniciais propostos, os dados foram coletados por meio de entrevistas em profundidade aplicadas a 12 coordenadores dos 14 cursos. As entrevistas seguiram um roteiro pré-estabelecido, 
considerando os serviços prestados pelos cursos à sociedade, bem como os conceitos de Desenvolvimento Regional.

Os dados coletados foram analisados por meio da técnica de análise de conteúdo. Segundo Bardin (2000, p. 42), a análise do conteúdo envolve "um conjunto de técnicas de análise das comunicações visando obter, por procedimentos, sistemáticos e objetivos de descrição do conteúdo das mensagens, indicadores (quantitativos ou não) que permitam a inferência de conhecimentos [...] destas mensagens". Da mesma forma, utilizou-se técnicas de análise descritiva para apresentar as informações analisadas. Segundo Reis e Reis (2002), estas técnicas são responsáveis por organizar, resumir e descrever aspectos importantes sobre um conjunto de características observadas, e, se necessário, realizar comparações entre as características.

\section{Apresentação e análise dos resultados}

A apresentação e a análise dos resultados do estudo estão organizadas em quatro subseções. Inicialmente, é apresentada a caracterização da UNOESC. Na sequência, são apresentadas e analisadas as percepções dos coordenadores dos cursos sobre o termo Desenvolvimento Regional e, em seguida, as ações e atividades desenvolvidas pelos cursos que contribuem para o desenvolvimento regional. E, por fim, são apresentadas e analisadas as contribuições geradas na comunidade regional pela formação dos egressos nos cursos da UNOESC-SMO.

\section{Universidade do Oeste de Santa Catarina (UNOESC)}

A Universidade do Oeste de Santa Catarina (UNOESC) foi criada em 1968 pelo poder público municipal de Joaçaba (Santa Catarina), e credenciada para atuar como instituição universitária em 14 de agosto de 1996 pelo Ministério da Educação (MEC), sendo mantida pela Fundação Universidade do Oeste de Santa Catarina (Funoesc) (UNOESC, 2019ª).

Classificada como uma universidade comunitária e sem fins lucrativos, a UNOESC é originada por uma lei municipal, não pertencendo a pessoas físicas. Em 2019, a UNOESC apresentava cinco campi, localizados em Joaçaba, Xanxerê, São Miguel do Oeste, Chapecó e Videira, além de seis unidades, sendo elas a de UNOESC de Campos Novos, de Capinzal, de Fraiburgo, de Maravilha, de Pinhalzinho, e de São José do Cedro (UNOESC, 2019ª).

Em 2018 a UNOESC contava com quase 50 mil profissionais formados. No ano de 2019, apresentava cerca de 50 cursos de graduação, 100 cursos de especialização (latu sensu), seis programas de mestrado e três programas de doutorado (stricto sensu). 
Contudo, no campus da UNOESC-SMO, objeto de estudo da presente pesquisa, eram oferecidos, em 2019, 14 cursos de graduação presenciais, além de cursos de pós-graduação organizados conforme a demanda regional, totalizando mais de 3.400 alunos. Seus cursos apresentavam-se divididos nas seis áreas do conhecimento científico denominadas pela UNOESC: Ciências Agrárias com o curso de Medicina Veterinária; Ciências da Educação com os cursos de Pedagogia e Licenciatura em Educação Física; Ciências Exatas e Tecnológicas, com os cursos de Arquitetura e Urbanismo, Ciências da Computação e Engenharia Civil; Ciência Jurídica com o curso de Direito; Ciências Sociais, com os cursos de Administração e Ciências Contábeis; e Ciências da Vida e Saúde; os bacharelados em Educação Física, Enfermagem, Farmácia, Fisioterapia e Psicologia (UNOESC, 2019c).

Da mesma forma, a UNOESC-SMO conta com auditório, biblioteca, Centro Esportivo, Centro Cultural, Centro Tecnológico, e o Hospital Veterinário de Pequenos Animais. Além disso, o campus dispõe de serviços gratuitos à comunidade envolvendo o atendimento jurídico, psicológico e fisioterapêutico por meio do Núcleo de Prática Jurídica, da Clínica de Psicologia e da Clínica de Fisioterapia (UNOESC, 2019b).

Do mesmo modo, a UNOESC funciona com base na tríade ensino, pesquisa e extensão. Desse modo, presta seus serviços por meio da oferta de cursos para qualificação profissional, além de desenvolver estudos e pesquisas que objetivam melhorar a qualidade de vida da população. Além disso, por meio da extensão promove o aprimoramento dos alunos, ultrapassando as salas de aulas, com espaços para atender o público e executar projetos, utilizando seus conhecimentos a serviço da comunidade (FUNOESC, 2018).

\section{Percepção dos coordenadores dos cursos da Unoesc São Miguel do Oeste sobre o termo Desenvolvimento Regional}

Com a aplicação das entrevistas aos coordenadores dos cursos da UNOESC-SMO, evidenciou-se percepções de que o desenvolvimento de uma região decorre do seu crescimento econômico e social, envolvendo o acesso à educação, emprego, renda, saúde, habitação, cultura, entretenimento e alimentação por parte da população. Dessa forma, percebeu-se indícios de que o desenvolvimento de uma região decorre da sua capacidade de gerenciar um conjunto de condições econômicas e sociais, que, juntas, refletem na elevação da qualidade de vida da população.

Em conformidade com os coordenadores de curso, Vasconcellos e Garcia (2014) colocam que o desenvolvimento envolve a racionalização da aplicação de recursos objetivando melhorar indicadores econômicos e sociais como pobreza, desigualdade, desemprego, bem como condições de moradia, saúde, alimentação e educação. Nesse sentido, a coordenadora do curso de Psicologia ressalta que o "Desenvolvimento envolve todos os aspectos que contribuem para a região ter um crescimento 
financeiro e social, proporcionando a expansão, o reconbecimento, e a rentabilidade para as pessoas que nela permaneçam [... ]”.

Dentro do contexto do crescimento social, os coordenadores de curso destacam a formação humana como um dos fatores que originam os processos de desenvolvimento. Segundo a coordenadora dos cursos de Pedagogia, Bacharelado e Licenciatura em Educação Física, o "Desenvolvimento regional projeta principalmente a questão do desenvolvimento bumano, porque as pessoas com formação superior conseguirão olhar para o seu espaço, e projetar os meios para obter o desenvolvimento [...]”. Por sua vez, a coordenadora do curso de Arquitetura e Urbanismo faz uma conexão entre a UNOESC, prestadora de serviços educacionais, e o Desenvolvimento Regional, " $A$ UNOESC, através de suas atividades, articula como cada profissão pode contribuir separadamente no desenvolvimento, e forma profissionais que consigam pensar no planejamento da região $[\ldots]^{\prime \prime}$.

Não obstante, o coordenador do curso de Ciências Contábeis reforça que "O desenvolvimento é construido com as pessoas vindo na universidade, absorvendo conbecimentos e aplicando na sua empresa, e no seu município. Isso desenvolve a região, pois se uma empresa cresce, ela vai ajudar a região a crescer [...]”. Neste sentido, Vila (2018, p. 95) destaca que os profissionais graduados em universidades "são mais propensos que os demais habitantes a assumir responsabilidades profissionais em algumas funções cruciais para o desempenho das organizações em que trabalham e, dessa forma, para a eficiência global conjunta do sistema econômico e social". Desse modo, observa-se que a educação da população, na concepção dos coordenadores de curso, é um dos meios propulsores ao alcance do Desenvolvimento Regional.

Do mesmo modo, a cultura, o entretenimento, o acesso à saúde, alimentação e habitação são outros pontos que, na percepção dos coordenadores do curso, contribuem para o desenvolvimento. Segundo o coordenador do curso de Ciências da Computação, "O desenvolvimento é um movimento de várias peças e de vários setores, que juntos fazem o mesmo acontecer [...]”. Além disso, na fala do coordenador do curso de Engenharia Civil, "O desenvolvimento envolve a junção da cultura e dos hábitos das pessoas em prol de um objetivo comum [...]".

No que se refere ao contexto do crescimento econômico, observa-se, conforme os coordenadores de curso, que o crescimento e a expansão das organizações regionais, além do acesso à ocupação, e à renda pela população, são as condições finais que permitem alcançar o desenvolvimento. Para o coordenador do curso de Administração, "O desenvolvimento é a melhoria da qualidade de vida das pessoas, por meio do acesso à ocupação, e à renda [...]”. Reforçando essa colocação, a coordenadora do curso de Fisioterapia acrescenta que "O desenvolvimento abrange o crescimento de todas as áreas $e$ organizações que afetam a população, como a área da agricultura, da saúde, do comércio, e assim por diante $[. .$.$] ".$

Por fim, o coordenador do curso de Direito ressalta outra questão importante sobre o desenvolvimento. Segundo este, "O desenvolvimento deve ser ambientalmente sustentável 
e permanente, não momentâneo [...]”. Em complemento, Vila (2018) enfatiza que além de promover uma distribuição equitativa da renda e da riqueza entre a população, o Desenvolvimento Regional deve englobar a melhoria da sustentabilidade ambiental nos sistemas de produção e consumo. Assim, além do desenvolvimento ser concebido como a melhoria de condições econômicas e sociais, ele também necessita ser contínuo e ambientalmente sustentável.

\section{Ações e atividades desenvolvidas pelos cursos da Unoesc São Miguel do Oeste que contribuem para o desenvolvimento regional}

Com base no tripé ensino, pesquisa e extensão, os cursos da UNOESC-SMO desenvolvem um conjunto de ações e atividades para, e juntamente com, a comunidade regional. Segundo os coordenadores dos cursos, ao comparar as ações e atividades da UNOESC-SMO, destaca-se a maior atuação dos cursos com ênfase nas atividades de ensino em comparação com a atuação nas atividades de pesquisa e de extensão.

As atividades de ensino, conforme Vila (2018), consistem na utilização de recursos materiais e humanos no intuito de ensinar e instruir alunos, ampliando seus conhecimentos e habilidades pessoais. Nesse sentido, os coordenadores colocam que todos os cursos da UNOESC-SMO apresentam atividades de ensino voltadas em específico na formação dos alunos com conhecimentos, habilidades e competências para atuarem, principalmente, na região, sendo propositores de melhorias nas diversas áreas que demandem atenção. Diante disso, o coordenador do curso de Administração cita o exemplo específico do seu curso, afirmando que "A Unoesc desenvolve o ensino, pesquisa e extensão, mas no nosso caso, no curso de Administração, a ênfase maior está no ensino, preparando profissionais qualificados para a região [...]".

Quanto às atividades de pesquisa, Vila (2018) afirma que seu papel nas universidades está ligado com o processo de produção de conhecimentos orientados à resolução de problemas e a geração de inovações. Conforme os coordenadores de curso, a UNOESC-SMO, por meio de seus professores e alunos bolsistas de iniciação científica, desenvolve projetos de pesquisa anualmente com o intuito de investigar e propor soluções a problemas, principalmente, de nível regional.

Segundo o coordenador do curso de Farmácia, "São desenvolvidos diversos projetos de pesquisa com bolsistas de iniciação científica, em alguns casos, havendo o envolvimento direto da sociedade, ou desenvolvidos isoladamente na instituição [...]". Ainda conforme o coordenador, os projetos de pesquisa com a participação da sociedade envolvem pacientes específicos, como exemplo, pessoas com obesidade, hipertensos e diabéticos. Quanto aos projetos de pesquisa desenvolvidos isoladamente, estes se desdobram no estudo de microrganismos patogênicos, na extração de princípios ativos de plantas e no desenvolvimento de loções, cremes, medicamentos e xaropes que podem ser utilizados pela sociedade. 
O coordenador do curso de Direto expõe que "São desenvolvidos projetos de pesquisa, avaliando desde crimes ambientais praticados pelos agricultores até situaçoes jurídicas que envolvem o convivio de pessoas na região [...]”. Da mesma forma, há diversos projetos de pesquisa relacionados ao estudo da saúde animal, da criação e bem-estar animal, além da produção e segurança de alimentos, saúde pública e proteção animal. Conforme a coordenadora do curso de Medicina Veterinária, "Essas pesquisas, através do auxílio dos alunos, objetivam trazer alguns beneficios que possam favorecer a sociedade [...]".

Destaca-se, ainda, a realização de projetos de pesquisa que objetivam estudar as características históricas e culturais da região, além de avaliar o planejamento urbano e regional. $\mathrm{Na}$ área de Ciências da Educação, são desenvolvidos poucos projetos de pesquisa, e quando realizados, são direcionados à investigação de práticas educativas. Já o coordenador do curso de Administração destaca que são desenvolvidos poucos projetos de pesquisa vinculados a editais de pesquisa oferecidos pela UNOESC-SMO. Porém, segundo o coordenador, "Os alunos são incentivados a realizar projetos de pesquisa, estudos de viabilidade, e planos de negócios nos trabalhos de conclusão de curso [... ]”.

No que se refere à extensão, Vila (2018) afirma que seu objetivo é proporcionar a mediação dos conhecimentos produzidos na universidade para a sociedade, podendo promover diferentes mudanças, sejam tecnológicas ou institucionais. Desse modo, conforme os coordenadores de curso, a UNOESC-SMO, por meio das atividades específicas de cada área, conta com diversos projetos de extensão que possibilitam a interação e o oferecimento de serviços educativos para a comunidade regional.

Conforme a coordenadora do curso de Medicina Veterinária "São realizadas campanhas de vacinação antirrábica, de controle de zoonose, castração animal, conscientização sobre doenças, além do atendimento de animais de pequeno porte na UNOESC-SMO [...]”. Além disso, por serem gratuitos, ou em alguns casos, apresentarem valores irrisórios, possibilita-se a prestação de serviços acessíveis para a população de baixa renda.

Segundo a coordenadora dos cursos de Pedagogia e Licenciatura em Educação Física, "Os cursos desenvolvem projetos de extensão com atividades de cultura, esportes e lazer, envolvendo professores, estudantes, e diplomados, além de desenvolver projetos sociais em escolas de 11 municipios [...]".

De acordo com a coordenadora do curso de Psicologia, "O curso de Psicologia desenvolve ao menos uma atividade por semestre que seja em prol da prevenção da saúde e da qualidade de vida da população [...]”. O curso de Fisioterapia, conforme sua coordenadora, "Realiza projetos de extensão com grupos de hipertensos e diabéticos, em hospitais e unidades de saúde. Além de oferecer grupos de atividades físicas para a comunidade por intermédio dos acadêmicos [...]”. E, o curso de Farmácia, conforme seu coordenador, "Oferece ações extensionistas voltadas à orientação junto ‘a sociedade sobre a utilização de medicamentos [...]”. 
Além disso, a UNOESC-SMO apresenta a clínica de atendimento psicológico e fisioterapêutico. Ambas funcionam com o apoio dos acadêmicos estagiários e situam-se dentro do espaço da UNOESC-SMO, objetivando atender a população que necessite dos serviços específicos oferecidos de forma gratuita. Ressaltando a importância das clínicas, em especial a de fisioterapia, a coordenadora do curso de Fisioterapia reforça que "Muitos municípios próximos da Unoesc trazem seus pacientes para realizar fisioterapia na instituição, e muitos outros solicitam vagas no espaço. Por isso, em virtude da demanda pela população aos serviços, planejamos expandir os atendimentos na instituição [...]”.

A UNOESC-SMO conta com o Núcleo de Práticas Jurídicas que atende a comunidade com serviços e orientações na área jurídica de forma gratuita. Segundo o coordenador do curso de Direito, em 2018, no Núcleo de Práticas Jurídicas, "Foram realizados 4.705 atendimentos para a comunidade, com o auxílio dos acadêmicos do curso, prestando informações para a população, faz̧endo mediações e conciliações, e auxiliando a população usufruir de seus direitos [...]”".

O curso de Arquitetura e Urbanismo, conforme sua coordenadora, "Desenvolve projetos de paisagismo para escolas, prefeituras, hospitais, e casas da região, sendo estes realizados por alunos do curso. Além disso, elabora cartilhas contra o crime para orientação da população, junto com a Polícia Militar [...]”. Com o mesmo intuito de auxiliar a comunidade, o coordenador do curso de Engenharia Civil, expõe que "São realizados semestralmente, pelos professores e alunos do curso, projetos de reformas de casas, onde os alunos voluntariam-se no intuito de planejar e realizar reparos em determinadas casas que demandem atenção [...]”. Por sua vez, com o viés educativo e tecnológico, o coordenador do curso de Ciências da Computação destaca outra contribuição importante dentro da área analisada, segundo ele "São elaborados projetos de extensão com idosos orientando sobre o uso e segurança da informática e suas tecnologias [...]”.

O coordenador do curso de Administração destaca o desenvolvimento de "Consultorias em empresas regionais, elaboração de flyers orientativos e educativos, orientacõos sobre planejamento e organização financeira, além de projetos de orientação profissional realizados em escolas da região, por intermédio dos seus alunos [...]”. Do mesmo modo, todos os cursos citados apresentam atividades de estágio em organizações, proporcionando maior inserção e influência das atividades da UNOESC-SMO na comunidade regional.

Contudo, as contribuições geradas pela IES na comunidade regional não dependem exclusivamente dela própria. Conforme Rego e Caleiro (2012, p. 02), “a capacidade de interação com os restantes agentes econômicos, sociais ou culturais, públicos ou privados, presentes no território, determina em grande parte o conjunto dos efeitos obtidos". Nesse sentido, os efeitos proporcionados pelas atividades de ensino, pesquisa e extensão da IES na sua comunidade regional serão mais significativos na medida em que esta se aproximar e se apropriar dos resultados gerados pela IES. 


\section{Contribuição gerada na comunidade regional pela formação dos egressos nos cursos da Unoesc São Miguel do Oeste}

Como resultados gerados na comunidade regional pela formação dos egressos nos cursos ofertados pela UNOESC-SMO, observaram-se indícios das seguintes categorias: inserção de profissionais qualificados no mercado de trabalho; elevação da intelectualidade da população regional; e resposta às demandas e necessidades da região. $\mathrm{Na}$ sequência, são avaliadas as referidas categorias em conjunto com as contribuições específicas proporcionadas pelos cursos da UNOESC-SMO.

No que tange a inserção de profissionais qualificados no mercado de trabalho, Vila (2018) afirma que as universidades oferecem um fluxo de indivíduos com alta qualificação, talentos e habilidades, proporcionando, a cada turma de formandos, o capital humano necessário para atender as novas exigências de qualificação profissional das organizações. Isso pode ser observado pela fala do coordenador do curso de Farmácia, que a UNOESC-SMO "Forma egressos com importante atuação no mercado regional, visto que existe carência de profissionais qualificados na região [...]". Além de fornecer profissionais qualificados para o mercado de trabalho, o coordenador do curso de Administração, coloca que a formação nos cursos "Possibilita a abertura do mercado de trabalho para a atuação do egresso [...]”.

Dentro deste contexto, a coordenadora do curso de Medicina Veterinária aborda o fato relevante de que a região Extremo Oeste de Santa Catariana, onde se localiza a UNOESC-SMO, contém forte participação da agropecuária na economia regional. Desse modo, a coordenadora coloca que os egressos do curso participam ativamente "Auxiliando no desenvolvimento da região, atuando principalmente na área de avicultura, suinocultura e produção leiteira, áreas as quais compõem a agropecuária regional [...]”. Cabe ressaltar que, entre 2017 e 2018, Santa Catarina se classificava entre os estados mais influentes na produção agropecuária brasileira, especialmente na produção de suínos, frangos, ostras, mexilhões, leite, entre outros produtos (SANTA CATARINA, 2019).

Em relação à elevação da intelectualidade da população regional, a área de Ciências da Educação se destaca pelo comprometimento de seus egressos em proporcionar e expandir a formação intelectual de indivíduos que se encontram em processo formativo. Conforme a coordenadora do curso de Pedagogia e Licenciatura em Educação Física, "Os egressos no decorrer da formação acadêmica, desenvolvem uma sólida formação humana e específica em sua área [...]”. Para a coordenadora, esta formação acadêmica "Permite o desenvolvimento de competências para auxiliar nos processos de formação e desenvolvimento intelectual de muitos outros sujeitos [...].

Nesse sentido, Serra, Rolim e Bastos (2018) acrescentam que a promoção de capital humano especializado e a intensificação do progresso tecnológico geram as circunstâncias para o surgimento de economias regionais mais eficientes e dinâmicas. Por sua vez, Vila (2018) reforça que a utilidade das universidades está vinculada com as capacidades e habilidades possibilitadas aos seus formados, além 
da aplicação de conhecimentos e inovações, oriundos da pesquisa científica, em empresas e organizações da sociedade no espaço geográfico ao qual atuam.

No que concerne o atendimento das demandas e necessidades da região, os coordenadores enfatizam a atuação dos seus egressos com base na formação obtida. Conforme a coordenadora do curso de Arquitetura e Urbanismo, "O curso de Arquitetura e Urbanismo forma profissionais capazes de pensar as cidades, entendendo como ocorrem as articulações regionais, permitindo auxiliar na sua organização e no planejamento regional [...]”. Por sua vez, o coordenador de Ciências da Computação explana que "Os egressos de Ciências da Computação podem dar suporte a qualquer área do conbecimento, em especial na área da tecnologia, a qual apresentam maior aprofundamento durante o curso [...]”. Para o coordenador do curso de Engenharia Civil, essa atuação dos egressos na sociedade ocorre "De forma ética, responsável e sustentável [...]".

$\mathrm{Na}$ área de Ciências da Vida e Saúde, os coordenadores dos cursos contribuem afirmando que seus egressos apresentam competências para planejar e atuar no intuito de promover a saúde, seja em hospitais, clínicas, consultórios, academias, entre outros espaços. Para o coordenador do curso de Farmácia "Os egressos são individuos com habilidades que permitem pensar a área da saúde a nivel regional [...]". Complementando, a coordenadora do curso de Bacharelado em Educação Física acrescenta que "Os egressos da área atuam possibilitando a promoção e o desenvolvimento da saúde $[\ldots]$ "..

O coordenador do curso de Direito expõe que a atuação dos egressos na região gera contribuições indispensáveis para o processo de acesso à Justiça por todos os cidadãos. Os coordenadores do curso de Administração e de Ciências Contábeis enfatizam que a atuação dos egressos é primordial para a manutenção e tomada de decisões empresariais. Segundo o coordenador do curso de Administração, "O administrador tem uma condição diferenciada dos outros profissionais, porque ele apresenta visão do mercado e procura adequar a empresa às especificidades desse mercado [...]”. Por sua vez, o coordenador do curso de Ciências Contábeis coloca que "O contador proporciona informações relevantes sobre as atividades empresariais, possibilitando os meios para auxiliar na tomada de decisões assertivas no mercado [...]”."

Diante disso, observa-se o propósito da UNOESC-SMO em influenciar no desenvolvimento regional por meio da realização de atividades voltadas ao processo de desenvolvimento humano. No que se refere ao processo de desenvolvimento humano, Grike, Santos e Oliveira (2018, p. 220) colocam que “a educação é uma forte aliada pois enquanto disponibiliza ao sujeito conhecimento este transforma a realidade social da qual está inserido desenvolvendo novas técnicas, e utilizando o saber para produzir novas formas de desenvolvimento e fortalecimento da sociedade".

Assim, pode-se compreender que a UNOESC-SMO apresenta comprometimento em formar egressos aptos a atuarem, principalmente, no espaço regional, com conhecimentos e competências que lhes permitem serem atores de processos 
individuais, que, somados, contribuem para o desenvolvimento de diferentes áreas na região, com maior ênfase na agropecuária, saúde, educação e gestão organizacional.

Do mesmo modo, conforme os coordenadores de curso, a UNOESC-SMO desenvolveu um papel determinante na região desde o início de suas atividades em 1986. A IES foi o ponto de partida para qualificar e especializar a população de São Miguel do Oeste (SC) e de diversos municípios localizados no entorno, os quais demandavam profissionais e que, em muitos casos, não apresentavam formação apropriada para atuação. Sendo assim, ressalta-se que a atuação da UNOESC-SMO é fundamental para o desenvolvimento pessoal e profissional da população e, consequentemente, para o desenvolvimento regional.

\section{Considerações finais}

O presente estudo teve como objetivo analisar a relação existente entre a UNOESCSMO e o desenvolvimento da região de atuação a partir da percepção dos coordenadores de curso.

As análises permitiram observar que, na percepção dos coordenadores de curso, o desenvolvimento de uma região resulta do seu crescimento econômico e social. Desse modo, para os coordenadores de curso, o desenvolvimento envolve condições de acesso à educação, emprego, renda, saúde, habitação, cultura, entretenimento e alimentação por parte da população. Sendo assim, o desenvolvimento de uma região decorre da sua capacidade em gerir condições econômicas e sociais, as quais refletem na elevação da qualidade de vida da população.

No que se refere às ações e atividades desenvolvidas pelos cursos da UNOESCSMO, evidenciou-se uma significativa participação e interação dos cursos com a comunidade regional. Observou-se que as seis áreas do conhecimento, por intermédio dos seus cursos, desenvolvem diferentes atividades no ensino, na pesquisa e na extensão, objetivando qualificar a população, auxiliar no estudo e resolução de problemas e possibilitar a transferência de conhecimentos da UNOESC-SMO para a comunidade regional. Ressalta-se, ainda, que para a maior parte dos coordenadores de curso, a UNOESC-SMO necessita expandir sua interação entre os próprios cursos existentes, bem como a comunidade regional.

No que tange os resultados gerados na comunidade regional pela formação dos egressos nos cursos da UNOESC-SMO, constatou-se o viés em formar alunos com habilidades e competências que contribuam no desenvolvimento, principalmente, da região de atuação. Evidenciou-se o compromisso da UNOESC-SMO em proporcionar egressos qualificados para o mercado de trabalho, que atendam às 
necessidades e demandas regionais, e que sejam propositores de melhorias no espaço regional no qual estão inseridos.

No que se refere à problemática de pesquisa, observou-se que a UNOESC-SMO apresenta uma série de relações e contribuições com o desenvolvimento de sua região de atuação. Sendo assim, por meio de suas ações e atividades, bem como da formação proporcionada aos egressos, a UNOESC-SMO pode ser reconhecida como um IES promotora do desenvolvimento regional. Esse fato é constatado pela atuação desempenhada pelos seus cursos, os quais permitem a criação e disseminação de um ciclo contínuo de conhecimentos e técnicas que resultam no desenvolvimento pessoal e profissional da sociedade envolvida. Além disso, desde a fundação da UNOESC-SMO, em 1986, a IES se propõe a atuar na região de São Miguel do Oeste, especializando e qualificando a população para às necessidades do mercado regional, reforçando a sua atuação em prol do desenvolvimento.

Quanto às limitações do estudo, salienta-se a dificuldade de obter informações sobre todas as ações e atividades desenvolvidas em cada curso. Sendo assim, sugere-se para estudos futuros, uma análise individual e detalhada de cada curso, obtendo um número maior de informações sobre as contribuições individuais de cada.

Com a conclusão deste estudo, pretende-se gerar reflexões que possibilitem aproximar-se da compreensão das relações entre as IES e o Desenvolvimento Regional, com enfoque específico no seu papel desempenhado e nas suas atividades desenvolvidas.

\section{Fonte(s) de Financiamento}

UNIEDU-Programa de Bolsas Universitárias de Santa Catarina.

\section{Referências}

BARDIN, Laurence. Análise de conteúdo. Lisboa: Edições 70, 2000. 225p.

BRASIL. Constituição da República Federativa do Brasil. Brasília: Senado Federal, 1988. 292p.

BRASIL. Decreto n. 9.235/17, de 15 de dezembro de 2017. Dispõe sobre o exercício das funções de regulação, supervisão e avaliação das instituições de educação superior e dos cursos superiores de graduação e de pós-graduação no sistema federal de ensino. Diário Oficial da União, Brasília, 15 de dezembro de 2017.

Disponível

em: 
http://legislacao.planalto.gov.br/legisla/legislacao.nsf/Viw_Identificacao/DEC \% 209.235-2017?OpenDocument. Acesso em: 05 dez. 2019.

CASADO, F. L.; SILUK, J. C. M.; ZAMPIERI, N. L. V. Universidade empreendedora e o desenvolvimento regional sustentável: proposta de um modelo. Revista de Administração da UFSM, v. 5, p. 633-649, 2012. http://dx.doi.org/10.5902/198346597755. Disponível em: https://periodicos.ufsm.br/index.php/reaufsm/article/view/7755/0. Acesso em: 15 mai. 2021.

CHIARELLO, I. S. A universidade e seu papel no desenvolvimento regional: contribuições do PROESDE. Revista Extensão em Foco, Caçador, 3 (1), p. 240 257 , 2015.

Disponível em: https://periodicos.uniarp.edu.br/index.php/245otmail245/article/view/795. Acesso em: 11 maio 2021.

CHIARINI, T.; VIEIRA, K. P.; ZORZIN, P. La Guardia. Universidades federais mineiras: análise da produção de pesquisa científica e conhecimento no contexto do sistema mineiro de inovação. Nova Economia, 22 (2), p. 307-332, 2012. http://dx.doi.org/10.5935/0103-4014.20180020. Disponível em: http://www.scielo.br/scielo.php?script=sci_arttext\&pid=S010363512012000200004\&lng=isso\&nrm=isso. Acesso em: 15 mai. 2021.

DIEHL, B. T.; TERRA, E; L. A indissociabilidade entre o ensino, a pesquisa e a extensão: do legal ao real. Revista de Humanidades, 28 (2), p. 166, 2017. http://dx.doi.org/10.5020/23180714.2013.28.2.166-185. Disponível em: https://periodicos.unifor.br/rh/article/view/6488. Acesso em: 13 mai. 2021.

FRANTZ, Walter. A extensão universitária no desenvolvimento regional: a leitura da experiencia de uma universidade mineira. In: III Fórum de Extensão Universitária da ACAFE, 2002, Lages/SC. Anais... Lages: Uniplac, 2002. 232p.

FUNOESC-FUNDAÇÃO UNIVERSIDADE DO OESTE DE SANTA CATARINA (Org.) E-book FUNOESC 50 anos. Joaçaba: Ed. Unoesc, 2018. 288p. Rogerio Augusto Bilibio (organizador). Disponível em: https://www.unoesc.edu.br/images/uploads/atendimento/Ebook_Funoesc_50_anos_\%281\%29.pdf. Acesso em: 15 mai. 2021. 
GIL, Antonio Carlos. Métodos e técnicas de pesquisa social. 6 ed. São Paulo: Atlas, 2008. 201p.

GOEBEL, M. A.; MIURA, M. N. A universidade como fator de desenvolvimento: o caso do município de Toledo-PR. Revista Expectativa, Toledo, 3 (1), p. 35-47, 2004. Disponível em: http://erevista.unioeste.br/index.php/expectativa/article/view/743. Acesso em: 12 mai. 2021.

GRIKE, F.; SANTOS, G. D.; OLIVEIRA, M. R. IDHM e a taxa de matrículas no ensino médio: uma análise multivariada dos maiores municípios que nomeiam as microrregiões do estado do Paraná. Revista Tecnologia e Sociedade, Curitiba, 14 (30), p. 217-237, 2018. http://dx.doi.org/10.3895/rts.v14n30.4623. Disponível em: https://periodicos.utfpr.edu.br/rts/article/view/4623. Acesso em: 15 mai. 2021.

HOFF, D. N.; MARTIN, A. S. San; SOPEÑA, M. B. Universidades e desenvolvimento regional: impactos quantitativos da UNIPAMPA em Santana do Livramento. Redes, Santa Cruz do Sul, 16 (3), p. 157-183, 2011. Disponível em: https://online.unisc.br/246ot/index.php/redes/article/view/1699. Acesso em: 12 mai. 2021.

INEP-INSTITUTO NACIONAL DE ESTUDOS E PESQUISAS EDUCACIONAIS ANÍSIO TEIXEIRA. Sinopse Estatística da Educação Superior 2000. Brasília: O Instituto, 2001. Disponível em: http://download.inep.gov.br/download/censo/2000/Superior/sinopse_superior2000.pdf. Acesso em: 02 dez. 2019.

INEP-INSTITUTO NACIONAL DE ESTUDOS E PESQUISAS EDUCACIONAIS ANÍSIO TEIXEIRA. Censo da Educação Superior: notas estatísticas 2017. Brasília: O Instituto, 2017. Disponível em: http://download.inep.gov.br/educacao_superior/censo_superior/documentos/2 018/censo_da_educacao_superior_2017-notas_estatisticas2.pdf. Acesso em: 02 dez. 2019.

JORDANI, Paulo Sergio et al. Fatores determinantes na escolha profissional: um estudo com alunos concluintes do ensino médio da Região Oeste de Santa Catarina. Revista ADMPG: Gestão Estratégica, Ponta Grossa, 7 (2), p. 25-32, 
2014. Disponível em: http://www.admpg.com.br/revista2014_2/Artigos/3\%20\%20Artigo_3.pdf. Acesso em: 12 mai. 2021.

MONDINI, V.; DAGNONI, E.; RODRIGUES, Maria José C. S. Entendendo a classificação das IES no Brasil. In: V COLOQUIO INTERNACIONAL SOBRE GESTIÓN UNIVERSITARIA EN AMÉRICA DEL SUR, 2005, Mar del Plata. Anais... Mar del Plata: INPEAU, 2005.

MONTEIRO NETO, Aristides; BRANDÃO, Carlos Antonio; CASTRO, César Nunes de. Desenvolvimento regional brasileiro: dilemas e perspectivas neste início de século XXI. In: MONTEIRO NETO, Aristides; BRANDÃO, Carlos Antonio; CASTRO, César Nunes de (Org.) Desenvolvimento regional no Brasil: políticas, estratégias e perspectivas. Rio de Janeiro: Ipea, p. 429-469, 2017.

OLIVEIRA, Gilson Batista de. Uma discussão sobre o conceito de desenvolvimento. Revista da FAE, Curitiba, 5 (2), p. 37-48, 2002. Disponível em: https://revistafae.fae.edu/revistafae/article/view/477/372. Acesso em: 14 mai. 2021.

RAMOS, A. J.; TURMENA, L.; NASCIMENTO, Z. M. A.. Inclusão dos jovens do campo no ensino superior: limites e possibilidades. Educar em Revista, Curitiba, n. 3, p. 167-189, 2017. http://dx.doi.org/10.1590/0104-4060.51044. Disponível em: $\quad$ http://www.scielo.br/scielo.php?script=sci_arttext\&pid=S010440602017000700167\&lng=pt\&nrm=isso. Acesso em: 12 mai. 2021.

REGO, M. C.; CALEIRO, A. Em torno do contributo das instituições de ensino superior para a dinâmica regional de crescimento económico. Drd: Desenvolvimento Regional em Debate, 2 (2), p. 124-138, 2012. http://dx.doi.org/10.24302/drd.v2i2.254. Disponível em: https://www.periodicos.unc.br/index.php/drd/article/view/254. Acesso em: 13 mai. 2021.

REIS, Edna Afonso; REIS, Ilka Afonso. Análise descritiva de dados: síntese numérica. Belo Horizonte: UFMG, 2002. 64 p.

ROLIM, Cássio; SERRA, Maurício. Ensino superior e desenvolvimento regional: avaliação do impacto econômico de longo-prazo. Revista Brasileira de Estudos 
Regionais e Urbanos, 3 (1), p. 85-106, 2009. Disponível em: https://www.revistaaber.org.br/rberu/article/view/29. Acesso em: 14 mai. 2021.

SALATA, André. Ensino Superior no Brasil das últimas décadas: redução nas desigualdades de acesso? Tempo Social, 30 (2), p. 219-253, 2018. http://dx.doi.org/10.11606/0103-2070.ts.2018.125482. Disponível em: http://www.scielo.br/scielo.php?script=sci_arttext\&pid=S0103-

20702018000200219\&lng=isso\&nrm=isso. Acesso em: 14 mai. 2021.

SANTA CATARINA. Síntese anual da agricultura de Santa Catarina 20172018. Florianópolis: Empresa de Pesquisa Agropecuária e Extensão Rural de Santa Catarina-EPAGRI/Secretaria de Estado de Agricultora e da Pesca. 2019. Disponível em: http://docweb.epagri.sc.gov.br/website_cepa/248otmail248ões/Sintese_2017_18 .pdf. Acesso em: 10 dez. 2019.

SERRA, Mauricio; ROLIM, Cássio; BASTOS, Paul. Universidade e a "mão visível" do desenvolvimento regional. In: SERRA, Maurício; ROLIM, Cássio; BASTOS, Ana Paula. Universidades e desenvolvimento regional: as bases para a inovação competitiva. Rio de Janeiro: Idead D, p. 83-122, 2018.

SLEUTJES, Maria Helena Silva Costa. Refletindo sobre os três pilares de sustentação das universidades: ensino-pesquisa-extensão. Revista de Administração Pública, Rio de Janeiro, 33 (3), p. 99-111, 1999. Disponível em: http://bibliotecadigital.fgv.br/ojs/index.php/rap/article/view/7639. Acesso em: 14 mai. 2021.

UNOESC-UNIVERSIDADE DO OESTE DE SANTA CATARINA. Conheça nossos Campi. 2019 . Disponível em: https://www.unoesc.edu.br/unoesc/conheca-unoesc. Acesso em: 02 dez. 2019.

UNOESC-UNIVERSIDADE DO OESTE DE SANTA CATARINA. Conheça a Unoesc São Miguel do Oeste. 2019b. Disponível em: https://www.unoesc.edu.br/unoesc/conheca-unoesc-single/saeo-miguel-dooeste. Acesso em: 02 dez. 2019. 
UNOESC-UNIVERSIDADE DO OESTE DE SANTA CATARINA. Cursos, 2019c. Disponível em: https://www.unoesc.edu.br/cursos. Acesso em: 02 dez. 2019.

VASCONCELLOS, Marco Antônio Sandoval de; GARCIA, Manuel Enriquez. Fundamentos de economia. 5 ed. São Paulo: Saraiva, 2014. 368p.

VILA, Luiz E. Abordagens micro e macro para o papel das universidades no desenvolvimento regional. In: SERRA, Maurício; ROLIM, Cássio; BASTOS, Ana Paula. Universidades e desenvolvimento regional: as bases para a inovação competitiva. Rio de Janeiro: Idead D, p. 83-122, 2018.

Data de submissão: 19/04/2020

Data de aprovação: 20/05/2021

Revisão: Daniela Matthes (português), Anderson de Miranda Gomes (inglês) e Yanet

María Reimondo Barrios (espanhol).

Fábio Zambiasi

Programa de Pós-Graduação em Desenvolvimento Regional / Universidade

Tecnológica Federal do Paraná (Campus Pato Branco)

Via do Conhecimento, km 01 - Bairro Fraron

85503-390 Pato Branco/PR, Brasil

Orcid: http://orcid.org/0000-0002-1497-0687

E-mail: fabiozambiasi@hotmail.com.br

Elis Regina Mulinari Zanin

Universidade do Oeste de Santa Catarina

Rua Oiapoc, 211 - Bairro Agostini

89900-000 São Miguel do Oeste/SC, Brasil

Orcid: http://orcid.org/0000-0003-1911-7834

E-mail: elis.zanin@unoesc.edu.br 
Fábio Zambiasi e Elis Regina Mulinari Zanin

250 | Revista Brasileira de Desenvolvimento Regional, Blumenau, 9 (2), p.227-250, 2021 